\title{
Evaluación de la cobertura vegetal en bofedales altoandinos en función de la napa freática y precipitación utilizando imágenes de satélite
}

\section{Evaluation of the vegetation cover in high Andean wetlands depending on the water table and precipitation using satellite images}

\author{
Luz Alexandra Javier Silva1, Edwin Portal Quicaña², Francisco Alejandro Alcántara Boza ${ }^{3}$ \\ Recibido: 28/02/2021 - Aprobado: 03/10/2021 - Publicado: 23/12/2021
}

\begin{abstract}
RESUMEN
El área de estudio comprendió el bofedal Minas Corral; Ayacucho, donde se determinó la relación entre la precipitación, el monitoreo de la napa freática, y la identificación de la variación de la cobertura vegetal, mediante el NDVI (índice de vegetación normalizada), con el uso de sensores remotos como satélites, que facilitan la recolección de información en un periodo de tiempo. Los datos de precipitación fueron obtenidos a partir de la estación meteorológica Apacheta, ubicado a $4150 \mathrm{msnm}$, en el distrito de Paras, provincia de Cangallo de la región Ayacucho, donde se validó la información en periodos mensuales. Para obtener la información sobre napa freática se tomaron 31 muestras en puntos de observación (piezómetros), de forma aleatoria y para la visualización de la variación mensual de cobertura vegetal se utilizaron imágenes del satélite Landsat 8. Se analizó la relación entre los parámetros definidos, desde el punto de vista espacial, donde se establecieron las correlaciones mensuales entre NDVI, precipitación y napa freática, los resultados obtenidos indican que existe una correlación alta e inversa de 97\% para las variables (Área de vegetación y napa freática) y directa de $49 \%$ (Área de vegetación y precipitación) y los resultados obtenidos por la prueba de independencia entre variables comprueban nuestra hipótesis. Por tanto, se concluye que la relación entre las variables (napa freática y precipitación) condiciona la extensión y un tipo de formación vegetal, los cuales varían en composición por estacionalidad.
\end{abstract}

Palabras claves: Bofedal; napa freática; precipitación; sensor remoto; NDVI (índice normalizado de vegetación); clasificación no supervisada; estación meteorológica; piezómetros.

\begin{abstract}
The study area included the Minas Corral wetland; Ayacucho, where the relationship between precipitation, groundwater monitoring, and the identification of vegetation cover variation was determined through NDVI (standardized vegetation index), with the use of remote sensors such as satellites, which facilitate the collection of information in a period of time. The precipitation data were obtained from the Apacheta meteorological station, located at 4150 masl, in the district of Paras, Cangallo province of the Ayacucho region, where the information was validated in monthly periods. To obtain the information on groundwater, 31 samples were taken at observation points (piezometers), randomly and for the visualization of the monthly variation of vegetation cover images of the Landsat 8 satellite were used. The relationship between the defined parameters was analyzed, from the spatial point of view, where the monthly correlations between NDVI, precipitation and groundwater were established, the results obtained indicate that there is a high and inverse correlation of $97 \%$ for the variables (Vegetation area and groundwater) and direct $49 \%$ (vegetation area and precipitation) and the results obtained by the test of independence between variables verify our hypothesis, Therefore, it is concluded that the relationship between the variables (groundwater and precipitation) conditions the extension and a type of plant formation, which vary in composition by seasonality.
\end{abstract}

Keywords: Wetland; groundwater; precipitation; remote sensor; NDVI (standardized vegetation index); unsupervised classification; meteorological station; piezometers.

\footnotetext{
1 Universidad Nacional Mayor de San Marcos, Lima, Perú. Geógrafa. Autor para correspondencia: lualiasigeo@gmail.com - ORCID: https://orcid.org/0000-0003-3346-7099

2 Universidad Nacional San Cristóbal de Huamanga. Biólogo, Docente. E-mail: eportalq@hotmail.com - ORCID: https://orcid.org/0000-0002-4192-0765

3 Universidad Nacional Mayor de San Marcos, Facultad de Ingeniería Geológica, Minas, Metalúrgica y Geográfica, Lima, Perú. Ingeniero Geógrafo, docente. E-mail: falcantarab@unmsm.edu.pe - ORCID: https://orcid.org/0000-0001-9127-4450
} 


\section{INTRODUCCIÓN}

La ecológica de los bofedales no son reconocidas a través de su importancia económica en una dimensión real, sin embargo, estos ecosistemas son recursos clave por la diversidad de fauna y flora que mantienen (Stotz, D. F., Fitzpatrick J. W., 1996), debido a que almacenan agua permitiendo el desarrollo de una diversidad vegetal (Ranga Myneni et al., 1995) en ambientes donde las condiciones climáticas no son favorables.

Los bofedales cumplen diversas funciones: 1. Producen de forma permanente forrajes para la alimentación de camélidos, 2. Por la característica predominante de inundación constante, los suelos tienen mayor acumulación de humus y materia orgánica, 3. Por lo general, los bofedales presentan buena del calidad, ya que; provienen de ríos o manantiales, 4. La presencia de bofedales influyen a un microclima de la zona circundante, 5. La cobertura vegetal recubre y protege los suelos contra la erosión de lluvias intensas; y 6 . Hábitat natural de flora y fauna silvestre (Convención de Ramsar, 2008).

Los bofedales poseen una alta dependencia del nivel de la napa freática y precipitaciones continuas de la época estacional de verano (García et al., 2020), el ecosistema generado en estos medios es capaz de tolerar variaciones de fuertes precipitaciones y periodos de sequía, pero siempre dentro de ciertos límites (Ahumada \& Faúndez, 2009).

Las raíces de las plantas de un bofedal extraen agua a una profundidad comprendida entre $1 \mathrm{~m}$ y $1 \mathrm{~m}$ y medio. El agua puede subir por los poros del suelo como máximo 50 cm, proceso conocido como "ascensor capilar", es decir; puede presentarse como problema el riego del bofedal si la napa freática tiene una profundidad mayor a $1 \mathrm{~m}$. Por tanto, si queremos determinar si el bofedal se seca debemos de realizar la medición de la profundidad de la napa freática (Centro de Ecología Aplicada-CEA, 2011).
La distribución de la precipitación dentro de un periodo anual y por temporadas, afecta de forma significativa al desarrollo y crecimiento de la vegetación, siendo la humedad una de las tantas propiedades del suelo que se relaciona con la productividad (Bonham, 2013).

La falta de agua en un bofedal ocasionaría su conversión a pajonal o en caso contrario las especies vegetales del lugar comenzarían a degradarse, y esto implica la conversión ecosistémica en base a pérdidas de la cadena alimentaria de primer orden como fuente de alimentación para la fauna local (Ahumada \& Faúndez, 2009).

Por tanto, el presente estudio tiene como objetivo evaluar la relación entre la cobertura vegetal, obtenido a partir de imágenes satélite, respecto a la napa freática y precipitación para el bofedal Minas Corral.

La hipótesis por desarrollar es, si existe relación dependiente entre la extensión de cobertura vegetal del bofedal Minas Corral, obtenido a partir de imágenes satélite, respecto a la napa freática y precipitación.

\section{MÉTODOS}

El área de estudio se centra en el bofedal Minas Corral que se encuentra ubicado en el distrito de Vinchos, provincia de Huamanga, región de Ayacucho. (Figura 1), de altitud 4,293 msnm, región Suni, y una superficie de 47.12 Ha.

Para el desarrollo de la investigación, se recurrió a la tecnología a través de las imágenes ópticas satelitales de observación terrestre con la finalidad de generar información temporal y espacial (Garcia \& Otto, 2015). Se consideraron cuatro (4) fases: Recolección de la información (datos meteorológicos e imágenes satelitales), análisis y tratamiento de los datos (preprocesamiento y procesamiento), campo (monitoreo de la napa freática

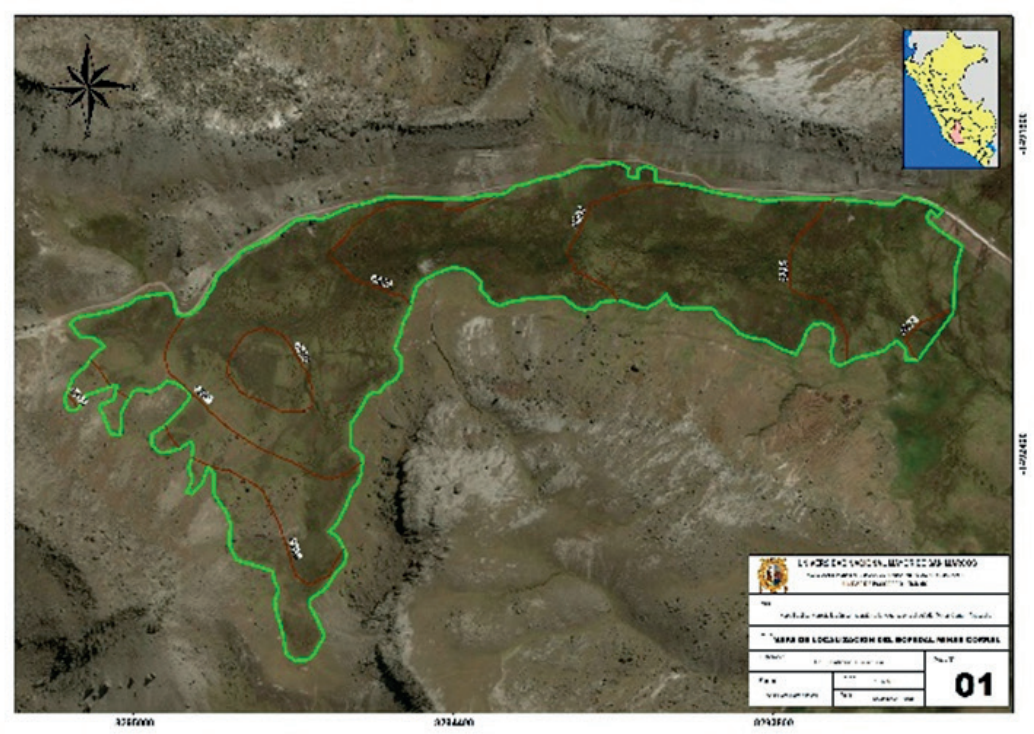

Figura 1. Mapa de localización del bofedal minas Corral - Ayacucho 
con piezómetros), gabinete (compilación de los datos); y análisis estadístico e interpretación de los resultados.

La Figura 2 representa un flujograma que explica los procesos y subprocesos para la obtención de los resultados.

En la fase de recolección de la información, se ingresó a las páginas de USGS (Science for changing world) y Copernicus Open Access Hub, para obtener el conjunto de datos de Landsat 8 y Sentinel 2, luego se procedió a realizar el preprocesamiento de la imagen con el software ENVI 5.4, mediante los procesos de corrección geométrica, (Itten \& Meyer, 1993); corrigiéndose los valores erróneamente registrados, o ruidos, entre otro tipo de alteración. Para este proceso se recurrió a la ortorectificación utilizando el módulo RCP Orthorectification Workflow e introduciendo al proceso el archivo DEM del área de estudio y la imagen satelital, luego se introdujeron puntos de control tomados en campo.
Corregidos los valores geométricos, se continuó con la corrección radiométrica (Ambrosio et al., 2002), (Brizuela et al., 2007), se restablecieron valores de los niveles digitales (ND), depurando anomalías como: errores debidos a la topografía, al efecto de la atmósfera en la radiación, etc.

Para terminar la etapa de preprocesamiento, se realizó con la corrección atmosférica (Aguilar Arias et al., 2015), se compensaron diferencias de iluminación solar, debido a la variación de altitudes en el terreno, por tanto; se aplicó la corrección atmosférica para eliminar el efecto causado por la dispersión de la radiación electromagnética originado por partículas y gases atmósfericos.

Para la etapa de procesamiento de la imagen satelital, comprendió la aplicación de la clasificación no supervisada, donde no es preciso un conocimiento preliminar del terreno para la identificación de las clases de cobertura, esto en

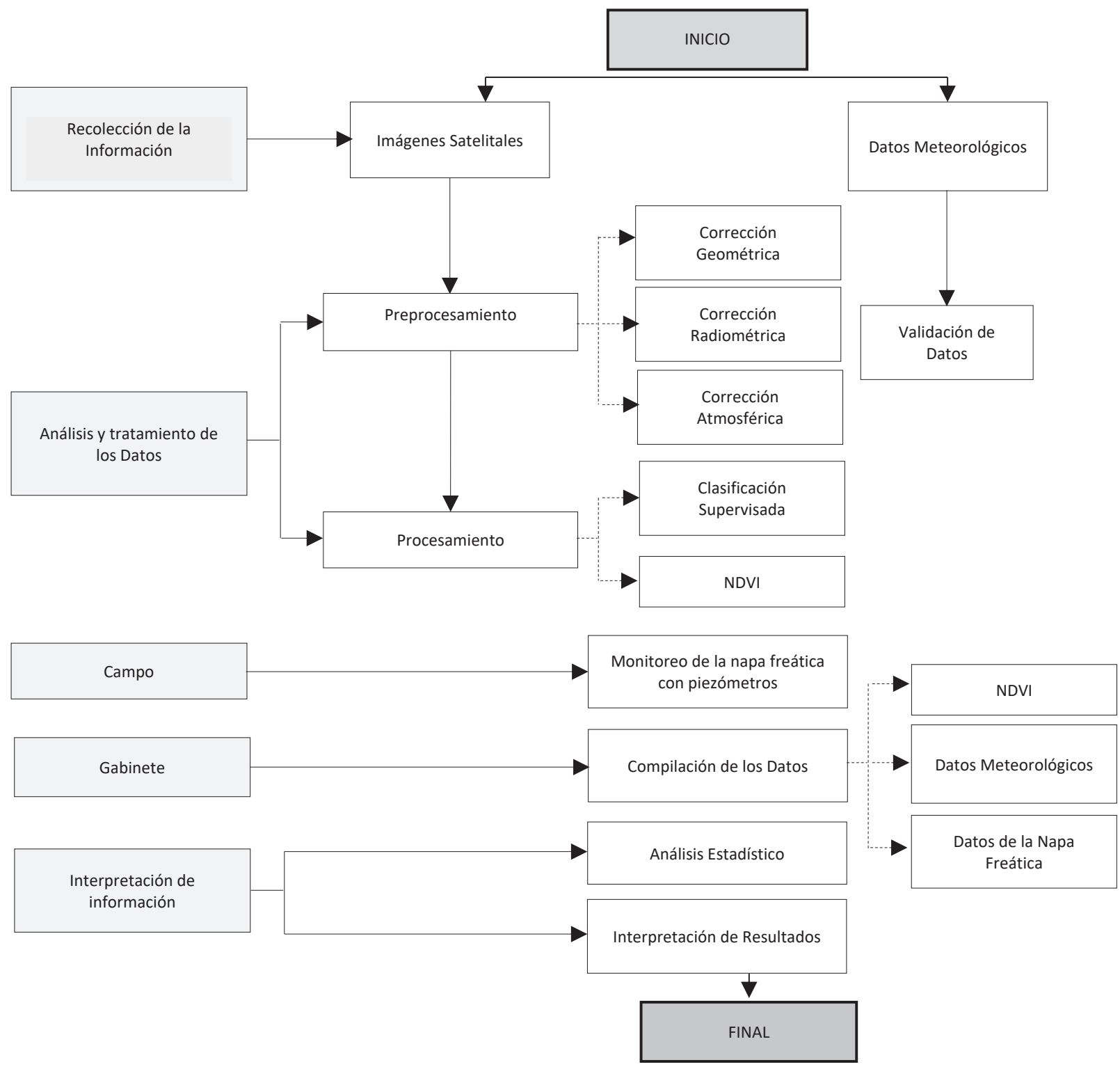

Figura 2. Flujograma de la investigación 
efecto de determinar de forma preliminar los límites de la extensión de la cobertura vegetal en determinados periodos de tiempo.

Finalmente se procedió a la extracción de la información sobre vegetación, mediante el uso de los índices de vegetación (Rueda Calier et al., 2015), los cuales permitieron detectar la presencia de vegetación y la actividad de esta, ya que sus valores están en relación con dicha actividad. Luego de aplicar el cálculo NDVI (Ranga Myneni et al., 1995) y (Baret \& Guyot, 1991), se recurrió al método de extracción de datos Density Slice, que mediante la determinación de umbrales se obtuvo datos sobre vegetación en formato vectorial.

En la etapa de campo se realizó de forma complementaria, una evaluación rápida para la vegetación, respecto a 31 puntos de observación, colocados uniformemente en función a la extensión del bofedal, empleando piezómetros (unidades muestrales $=1 \mathrm{~m}^{2}$ ), y dentro de estas unidades muestrales se distribuyeron puntos formando una cruz a distancias de $1 \mathrm{~m}$, la extracción de $0.25 \mathrm{~m}^{2}$ para su análisis (Vásquez Lam, 2008).

Para la medición de la napa freática, se determinaron 31 puntos de observación (piezómetros) seleccionados de forma aleatoria, (Chiong, 2015) señala que se utilice como mínimo 20 puntos de observación para áreas de $100 \mathrm{Ha}$, por otra parte (Montoya M, 2013) y (Cassalett \& Ranjel, 1995), recomienda un mínimo de 18 puntos sin interesar el tamaño del área en evaluación.

Para el muestreo del nivel de freático se consideró la periodicidad mensual durante un año, (enero - diciembre) con la ayuda del sensor conocido como freatímetro BLT (medidor de nivel de agua), (Portal Quicaña, 2019). El procedimiento realizar para la selección de los puntos, se realizó según lo recomendado por (Cassalett \& Ranjel, 1995). Las muestras se ubicaron en el sentido del flujo del nivel freático en paralelo al drenaje natural del área, 2. La distribución de las muestras se realizó de modo que los puntos formen una red de piezómetros de observación y 3. Se trató de evitar que la ubicación de los piezómetros se encuentre en forma de borde lineal como un río, canal, otros. (Ver Figura 3)

Los datos de precipitación fueron obtenidos a partir de la estación meteorológica Apacheta, obtenidos del SENAMHI, fuente estatal confiable según la (Organización Meteorológica Mundial, 1996), que plantea las condiciones que los instrumentos deben de cumplir, establecer las condiciones del lugar para realizar las medidas, los horarios adecuados para la toma y el grado de exactitud por cada variable.

La medición para la precipitación se realizó con pluviómetros tradicionales (mecánicos), compuestos por un receptor de $200 \mathrm{~cm}^{3}$, un embudo debajo y un tanque de almacenamiento. Al momento de tomarse los datos se observó en el pluviómetro la altura hasta donde llegaba la precipitación acumulada (Organización Meteorológica Mundial, 1996)

Luego se procedió al análisis de los datos meteorológicos mensuales y diarios (Serrano Vincenti et al., 2012), para las variables Napa freática, precipitación y área de vegetación.

\section{RESULTADOS y DISCUSIÓN}

Se procesaron y compilaron datos para la obtención de un único cuadro en base a un monitoreo en base a periodos mensuales para área de vegetación $(\mathrm{Ha})$, napa freática $(\mathrm{m})$ y precipitación (mm). (Ver Tabla 1$)$.

El mapa de monitoreo mensual para la cobertura vegetal, en cuanto a extensión, según el comportamiento estacional, indica que para los meses de diciembre a mayo periodo húmedo, presentó una extensión de $54 \%$, y para los meses de junio a noviembre periodo seco una extensión $46 \%$, con una variación de $8 \%$. (Ver Figura 4).

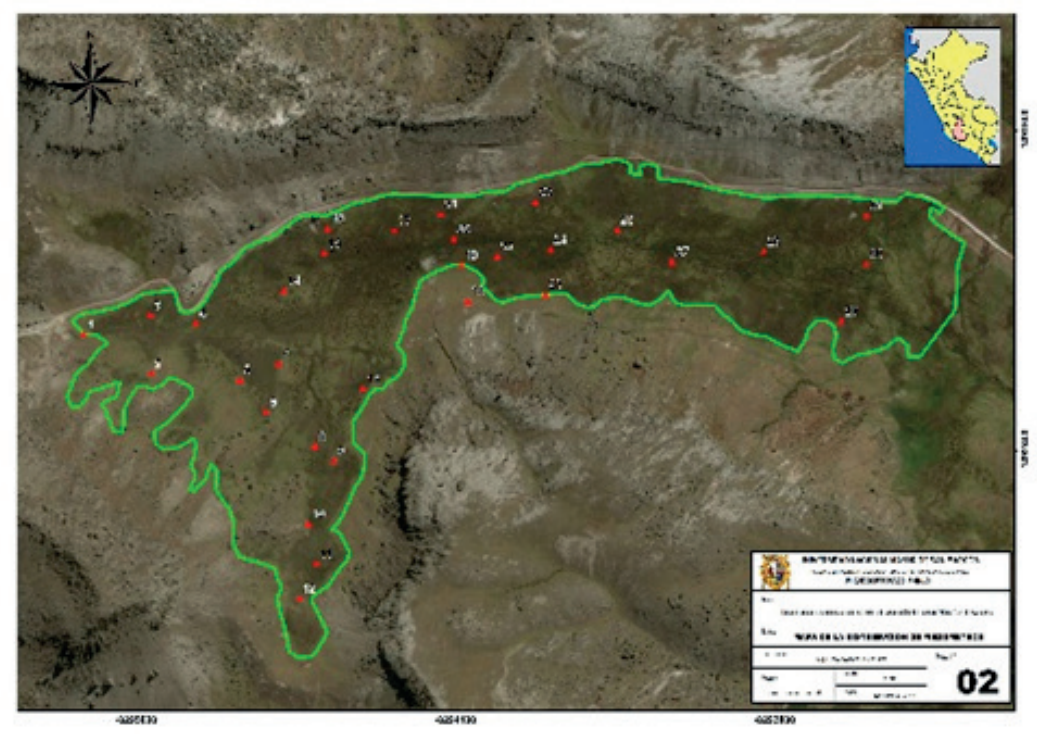

Figura 3: Mapa de la distribución de piezómetros 
Tabla 1. Datos de Área de vegetación, Napa freática y precipitación

\begin{tabular}{lccc}
\hline & Área de Vegetación $(\mathrm{Ha})$ & Napa Freática $(\mathrm{m})$ & Precipitación $(\mathrm{mm})$ \\
\hline Ene & 5.74 & 13.42 & 162.73 \\
Feb & 5.68 & 11.79 & 133.86 \\
Mar & 5.61 & 15.25 & 128.28 \\
Abr & 5.70 & 15.45 & 42.55 \\
May & 5.55 & 20.74 & 16.09 \\
Jun & 5.16 & 42.55 & 5.10 \\
Jul & 4.92 & 55.10 & 5.80 \\
Ago & 4.92 & 69.74 & 13.29 \\
Set & 4.89 & 73.84 & 58.33 \\
Oct & 4.54 & 79.71 & 48.56 \\
Nov & 4.33 & 83.34 & 49.49 \\
Dic & 5.30 & 38.71 & 147.87 \\
\hline
\end{tabular}

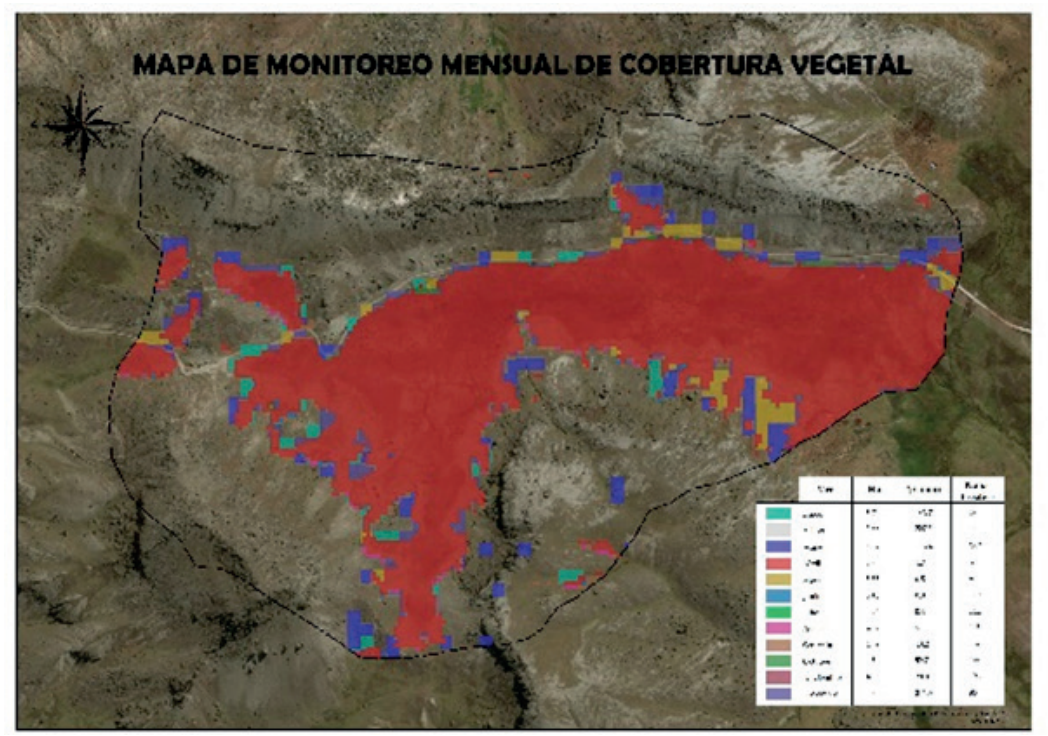

Figura 4. Mapa de monitoreo mensual de cobertura vegetal

En las investigaciones de (Loza Herrera et al., 2015), (Squeo et al., 2006), (Ruthsatz, 2012) se realizaron inventarios de especies encontrándose un total de 85 con 533 individuos, divididos en 28 familias. Las especies que se presentan en mayor cantidad en la cobertura vegetal del bofedal son: Plantago tubulosa Decne (Familia Plantaginaceae) y Distichia muscoide (Familia Juncaceae), , y según la metodología planteada por (Mostacedo \& Fredericksen, 2000) donde elaboraron un manual en base a métodos de muestreo y análisis para ecología vegetal.

La dinámica ecológica de un bofedal condiciona un tipo de formación vegetal, encontrándose 3 tipos: 1. Vegetación hidromórfica, 2. Mésica y 3. Borde, diferenciados por la relación que guardan con la humedad del suelo, según la investigación de (Macari Rosales \& Leiva Painequeo, 2013).

Por tanto, en el área de estudio se distinguen 3 zonas: 1. Zona húmeda e inundable donde se evidencia la vegetación hidromórfica (predominan especie acuáticas), su profundidad depende del estado de conservación de la cuenca; 2. Zona intermedia (mayor actividad forrajera y biológica) y 3 . Zona periférica (predominan vegetación herbácea), coincidiendo con las investigaciones de (Alzérreca, H., Prieto, G., Laura, J., D, L., Laguna, 2015). La Figura 5 muestra la distribución de piezómetros con relación a la topografía.

El análisis de correlación de Pearson entre variables, indica que para las variables área de vegetación y napa freática es fuerte e inversa (97\%), según la regresión cuadrática, es decir; a menor distancia de la napa freática con el suelo, mayor será la vegetación, diferenciando la formación vegetal del bofedal en su composición, como lo plantea en su investigación (Maldonado M., Valencia N., Ledesma K., 2017).

La relación entre las variables área de vegetación y precipitación es baja y directa (49\%), según la regresión logarítmica, interpretándose que a mayor precipitación mayor vegetación, esto quiere decir que un bofedal funciona como esponja porque libera el agua cuando 
las precipitaciones se reducen drásticamente, esto es en época seca (Squeo et al., 2006), (Benavides et al., 2013) y (Zeballos et al., 2014). Ver Figura 6 y Figura 7.
A partir de la temporalidad, la línea tendencial es prácticamente lineal, comprobando lo descrito en la investigación de (Belda et al., 1999) donde la correlación

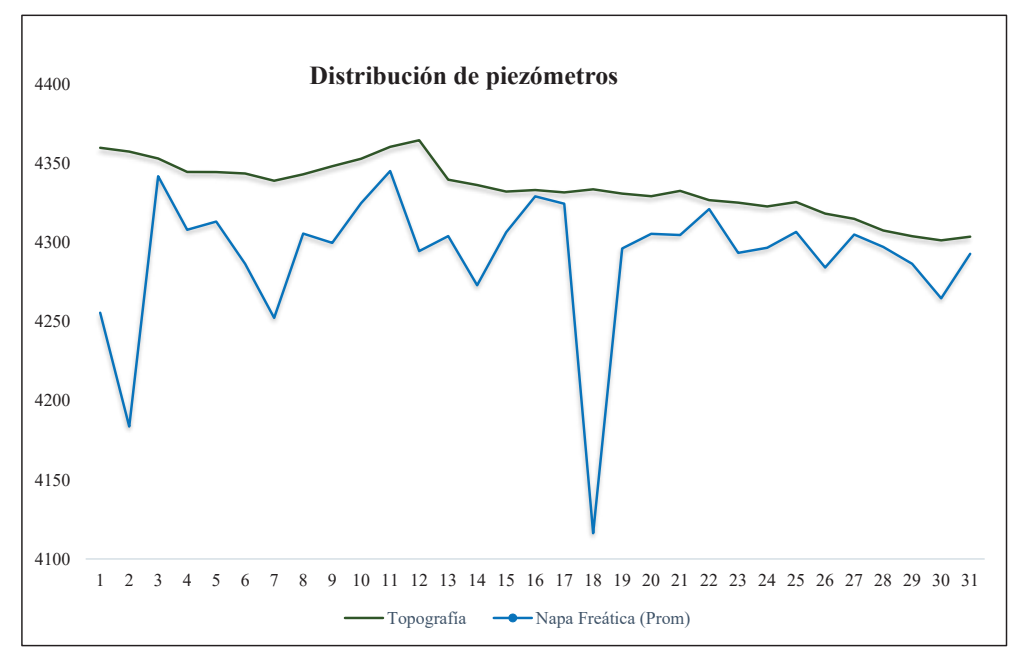

Figura 5. Distribución de piezómetros

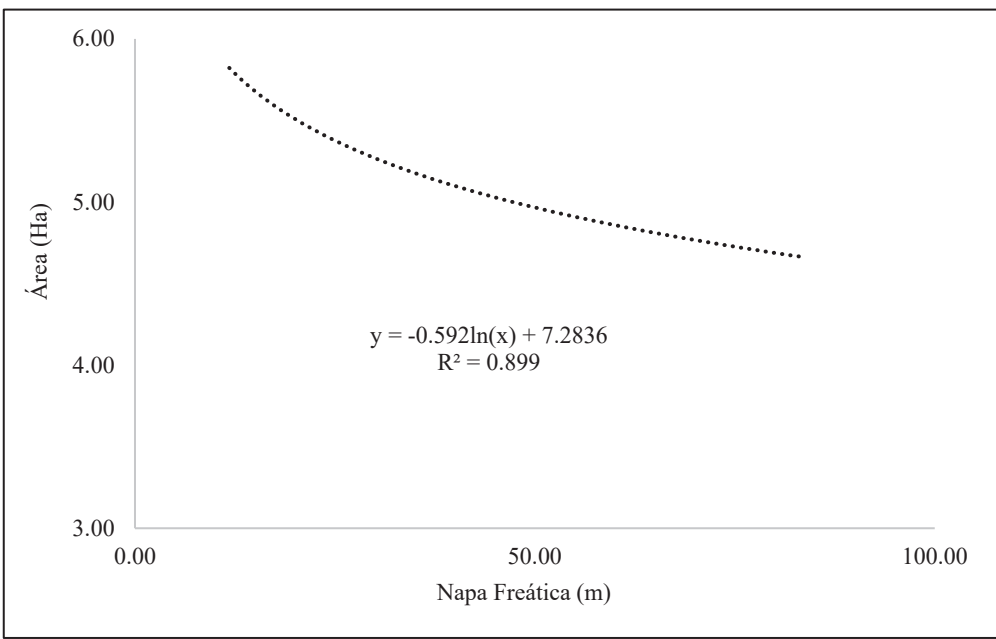

Figura 6. Correlación entre el área de la vegetación y la napa freática

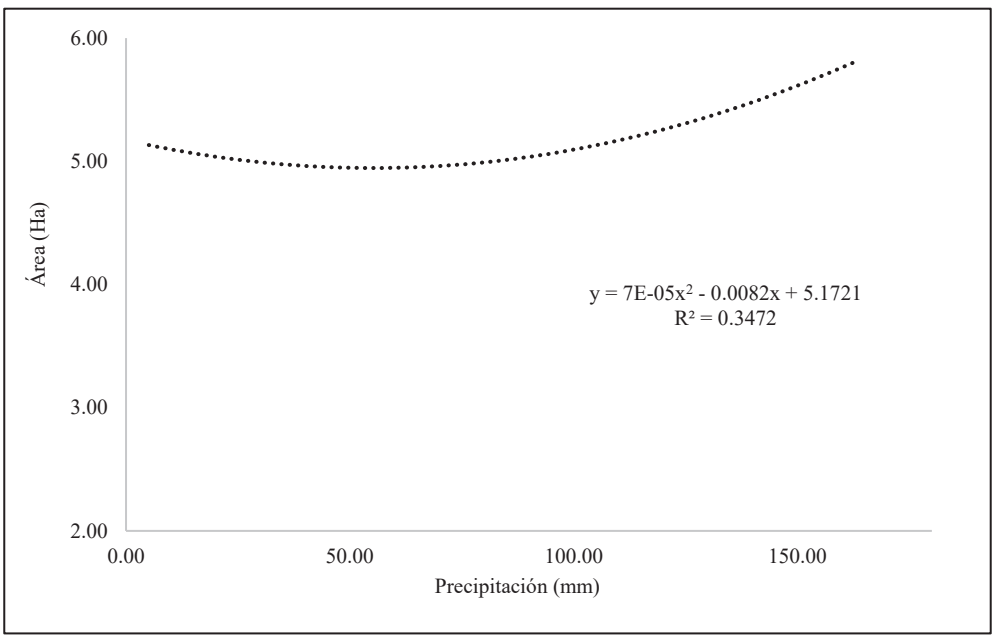

Figura 7. Correlación entre el área de la vegetación y la precipitación 
lineal entre la vegetación y precipitación decrece en los meses de estación otoño o invierno, sin embargo, las precipitaciones que se dan en la estación de primavera mejoran el ajuste lineal.

El nivel de significancia utilizado fue de 95\%, obteniendo un Chi-cuadrado de Pearson de 33.92, y frente al Chi-prueba 495.57, cayendo en la zona de rechazo para nuestra hipótesis nula (H0), por tanto, se comprueba nuestra hipótesis (H1): "Existe relación dependiente entre la extensión de cobertura vegetal del bofedal Minas Corral, obtenido a partir de imágenes satélite, respecto a la napa freática y precipitación" (Ver Figura 8).

\section{CONCLUSIONES}

- Se determinó que la correlación entre las variables área de vegetación y napa freática, indica una relación lineal perfecta negativa, lo cual explicaría en gran medida el comportamiento de la extensión en área de la vegetación del bofedal; finalmente para la correlación entre las variables área de vegetación y precipitación es débil, indicando una relación no lineal.

- $\quad$ Los bofedales, generalmente en época seca (abril) se encuentran en su máxima extensión de área, ya que; el reservorio de agua subterránea queda lleno después de pasar por la época de lluvias. Entonces, el reservorio de agua subterránea va disminuyendo al igual que el nivel de la napa freática a medida que avanza la época seca, y esto trae como consecuencia una relación directa en la disminución de la extensión de los bofedales.

- Ya que, los bofedales tienen agua tanto en la época seca como en la época húmeda debido a las variables mensuales precipitación $(67.66 \mathrm{~mm})$ y napa freática $(43.30 \mathrm{~m})$, la vegetación tiene una variación mínima tanto en composición y extensión $(5.19 \mathrm{Ha})$.

\section{REFERENCIAS}

Aguilar Arias, H., Mora Zamora, R., \& Vargas Bolaños, C. (2015). Metodología para la corrección atmosférica de imágenes ASTER, Rapideye, Spot 2 y Landsat 8 con el módulo Flaash del software ENVI. Revista Geográfica de América Central, 2(53), 39-59.

Ahumada, C., \& Faúndez, L. (2009). Guía descriptiva de los sistemas vegetacionales azonales hídricos terrestres de la ecorregión altiplánica.

Alzérreca, H., Prieto, G., Laura, J., D, L., Laguna, S. (2015). Características y distribución de los bofedales en el ámbito Boliviano. ASOCIACION INTEGRAL DE GANADEROS EN CAMELIDOS DE LOS ANDES ALTOS (AIGACAA), 1, 190.

Ambrosio, G., González, J., \& Arévalo, V. (2002). Corrección radiométrica y geométrica de imágenes para la detección de cambios en una serie temporal. X Congreso de Métodos Cuantitativos, Sistemas de Información Geográfica y Teledetección, (9).

Baret, F., \& Guyot, G. (1991). Potentials and limits of vegetation indices for LAI and APAR assessment. Remote Sensing of Environment, 35(2-3), 161-173. https://doi. org/10.1016/0034-4257(91)90009-U

Belda, F., Melia, J., \& Segarra, D. (1999). Relación entre el NDVI, precipitación y humedad del suelo. Aplicación a zonas forestales de la provincia de Alicante. VII Congreso Nacional de Teledetección, 80-83.

Benavides, J. C., Vitt, D. H., \& Wieder, R. K. (2013). The influence of climate change on recent peat accumulation patterns of Distichia muscoides cushion bogs in the high-elevation tropical Andes of Colombia. Journal of Geophysical Research: Biogeosciences, 118(4), 1627-1635. https://doi. org/10.1002/2013JG002419

Bonham, C. D. (2013). Measurements for Terrestrial Vegetation: Second Edition. In Measurements for Terrestrial Vegetation: Second Edition (2da. ed.). Wiley-Interscience. https://doi. org/10.1002/9781118534540

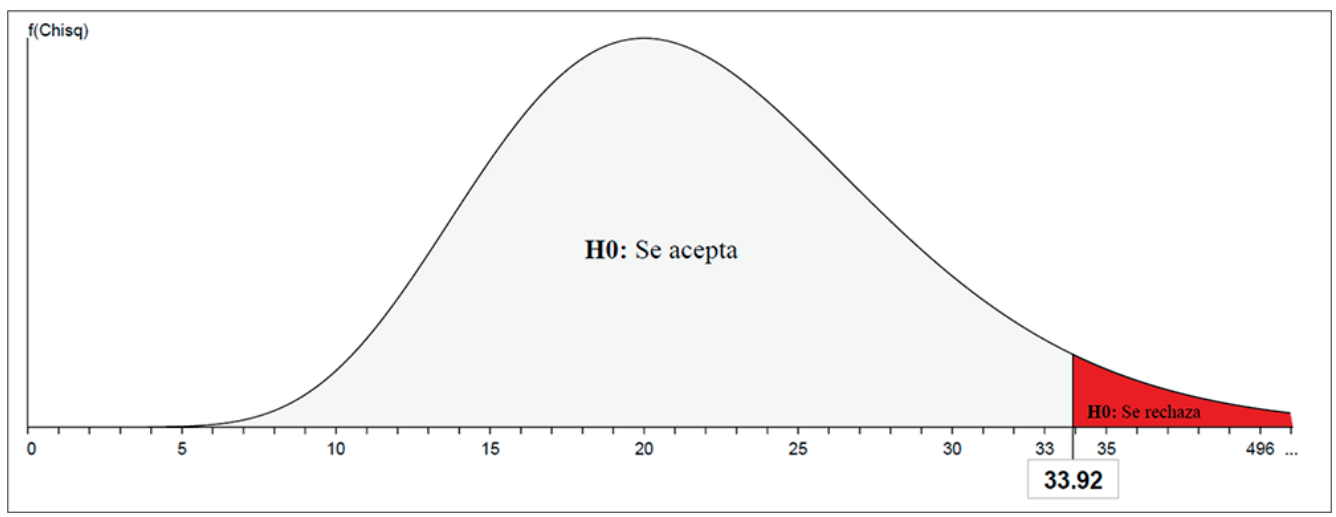

Figura 8. Gráfica chi-cuadrado 
Brizuela, A. B., Aguirre, C., \& Velasco, I. (2007). Aplicación de métodos de corrección atmosférica de datos Landsat 5 para análisis multitemporal. Remote Sensing of Environment, 207-214.

Cassalett, C., \& Ranjel, H. (1995). Mejoramiento genético. El cultivo de la caña en la zona azucarera de Colombia. In Centro de Investigación de la Caña de Azúcar de Colombia, Cali (Colombia).

Centro de Ecología Aplicada-CEA. (2011). Diseño del Inventario Nacional de Humedales y el Seguimiento Ambiental. Ministerio de Medio Ambiente. Santiago. 1-172.

Chiong, C. (2015). Estimación de la recarga del acuifero RimacSector Ate, mediante el riego de áreas verdes. Universidad Agraria La Molina - UNALM.

Convención de Ramsar. (2008). Estrategia regional de conservación y uso sostenible de los humedales altoandinos. Convención de Ramsar y Grupo de Contacto EHAA, Euroecuatoriana Indgrafsa S. A., 34.

Garcia, E., \& Otto, M. (2015). Caracterización ecohidrológica de humedales alto andinos usando imágenes de satélite multitemporales en la cabecera de cuenca del Río Santa, Ancash, Perú. Ecología Aplicada, 14(1-2), 115. https://doi. org/10.21704/rea.v14i1-2.88

García, J., Guerrero, J., Willems, B., \& Espinoza, R. (2020). Propuesta de un Índice de Bofedal para la Teledetección de Bofedales en Cabeceras de Cuenca Usando Datos Imágenes de los Sensores TM, OLI a bordo de los Satélites Landsat Caso Estudio: Bofedal Chunal, Cuenca Alta del río Chillón. Revista de Investigación de Física, 24(2), 23-30. https://doi. org/10.15381/rif.v24i2.20385

Itten, K. I., \& Meyer, P. (1993). Geometric and Radiometric Correction of TM Data of Mountainous Forested Areas. IEEE Transactions on Geoscience and Remote Sensing, 31(4), 764-770. https://doi.org/10.1109/36.239898

Loza Herrera, S., Meneses, R., \& Anthelme, F. (2015). Comunidades vegetales de los bofedales de la Cordillera Real (Bolivia) bajo el calentamiento global. Ecología En Bolivia: Revista Del Instituto de Ecología, 50(1), 39-56.

Macari Rosales, O., \& Leiva Painequeo, E. (2013). Manual de evaluación y manejo de bofedales.

Maldonado M., Valencia N., Ledesma K., V. B. y L. P. R. (2017). Dinámica interanual de la vegetación de bofedales sujetos a efectos de infraestructura lineal en la sierra sur del Perú 2009-2010. Congreso Peruano de Humedales. https://www.researchgate.net/publication/324953122 DINAMICA INTERANUAL DE LA VEGETACION ${ }^{-}$ DE BOFEDALES SUJETOS A EFECTOS DE INFRAESTRUCTURA LINEA $\bar{L}$ EN LA SIERRA SUR_DEL_PERU_2009-2015

Montoya M, S. (2013). Optimización de Costos ( y Tiempo ) en Estudios Hidrogeológicos. Gidahatari Agua.
Mostacedo, B., \& Fredericksen, T. (2000). Manual de métodos básicos de muestreo y análisis en ecología vegetal. Proyecto de Manejo Forestal Sostenible (BOLFOR) (Proyecto de Manejo Forestal Sostenible (BOLFOR), Ed.).

Organización Meteorológica Mundial. (1996). Guía de Instrumentos y Métodos. In OMM (Quinta edi, Vol. 3).

Portal Quicaña, E. (2019). Influencia de la Napa freática sobre la vegetación y capacidad de carga animal en bofedales altoandinos. In Universidad Nacional Mayor de San Marcos. UNIVERSIDAD NACIONAL MAYOR DE SAN MARCOS

Ranga Myneni, B., Forrest Hall, G., Piers Sellers, J., \& Alexander Marshak, L. (1995). Interpretation of spectral vegetation indexes. IEEE Transactions on Geoscience and Remote Sensing, 33(2), 481-486. https://doi.org/10.1109/36.377948

Rueda Calier, F., Peñaranda Mallungo, L. A., Velásquez Vargas, W. L., \& Díaz Báez, S. A. (2015). Aplicación de una metodología de análisis de datos obtenidos por percepción remota orientados a la estimación de la productividad de caña para panela al cuantificar el NDVI (índice de vegetación de diferencia normalizada). Ciencia \& Tecnología Agropecuaria, 16(1), 25-40. https://doi.org/10.21930/rcta. vol16_num1_art:377

Ruthsatz, B. (2012). Vegetation and ecology of the high Andean peatlands of Bolivia. Phytocoenologia, 42(3-4), 133-179. https://doi.org/10.1127/0340-269X/2012/0042-0535

Serrano Vincenti, S., Zuleta, D., Moscoso, V., Jácome, P., Palacios, E., \& Villacís, M. (2012). Análisis estadístico de datos meteorológicos mensuales y diarios para la determinación de variabilidad climática y cambio climático en el Distrito Metropolitano de Quito. La Granja, 16(2), 23. https://doi. org/10.17163/lgr.n16.2012.03

Squeo, F. A., Warner, B. G., Aravena, R., \& Espinoza, D. (2006). Bofedales: High altitude peatlands of the central Andes. Revista Chilena de Historia Natural, 79(2), 245-255. https://doi.org/10.4067/S0716-078X2006000200010

Stotz, D. F., Fitzpatrick J. W., P. T. A. \& M. D. K. (1996). Neotropical Birds: Ecology and Conservation. University of Chicago Press, 502.

Vásquez Lam, M. (2008). Comparación de dos métodos de muestreo para el estudio de la comunidad herbácea de Las Lomas. Zonas Aridas, 12(1), 166-183.

Zeballos, G., Soruco, Á., Cusicanqui, D., Joffré, R., Rabatel, A., Zeballos, G., Soruco, Á., Cusicanqui, D., Joffré, R., \& Rabatel, A. (2014). Uso de imágenes satelitales, modelos digitales de elevación y sistemas de información geográfica para caracterizar la dinámica espacial de glaciares y humedales de alta montaña en Bolivia. Ecología En Bolivia, 49(3), 14-26. 